\title{
REVISTA CIENTÍFICA ACERTTE
} ISSN 2763-8928

\section{ABASTECIMENTO DE CARROS ELÉTRICOS A PARTIR DA ENERGIA SOLAR \\ SUPPLY OF ELECTRIC CARS FROM SOLAR ENERGY}

\author{
Lucas Gomes Gélio ${ }^{1}$, Francisco Ignácio Giocondo César ${ }^{2}$
}

\section{RESUMO}

Carros elétricos têm ganhado espaço nos mercados da automobilística, um mercado que atualmente, em sua maioria, é dominado por veículos com motor à combustão interna. Em uma perspectiva em curto prazo, os veículos elétricos irão substituir os veículos à combustão em sua grande maioria. Com essa popularização e expansão mercadológica, vê-se necessário o desenvolvimento de sistemas de recargas mais descentralizados e fontes alternativas de energia, tais como a solar, se tornando possível a geração elétrica pelo próprio consumidor, assim como a diminuição da emissão de gases poluentes, auxiliando na desaceleração do efeito estufa no planeta. Esta pesquisa tem por objetivo estudar os meios de abastecimento de carros elétricos a partir da energia solar, observando as tecnologias envolvidas e as mais diversas formas de captação da energia solar. Foi desenvolvida a partir de um levantamento bibliográfico, exploratório, utilizando as bases de dados Web of Science e o Google Acadêmico. É esperado demonstrar a relação dos carros elétricos com a energia solar a partir de seu abastecimento, observando as tecnologias envolvidas, analisando as melhorias realizadas atualmente e o que falta ser feito, para que seja possível a utilização de bombas de abastecimento carregadas à energia solar.

PALAVRAS-CHAVE: Veículos Elétricos. Energia Solar. Placas Fotovoltaicas

\begin{abstract}
Electric cars have been gaining ground in the auto industry, a market that is currently mostly dominated by vehicles with an internal combustion engine. In a short-term perspective, electric vehicles will replace combustion vehicles for the most part. With this popularization and market expansion, it is necessary to develop more decentralized recharge systems and alternative energy sources, such as solar, making electricity generation possible by the consumer, as well as reducing the emission of polluting gases, helping to slow down the greenhouse effect on the planet. This research aims to study the means of supplying electric cars using solar energy, observing the technologies involved and the most diverse ways of capturing solar energy. It was developed from an exploratory bibliographic survey, using the Web of Science and Google Scholar databases. It is expected to demonstrate the relationship of electric cars with solar energy from their supply, observing the technologies involved, analyzing the improvements currently made and what remains to be done, so that it is possible to use supply pumps charged with solar energy.
\end{abstract}

KEYWORDS: Electric Vehicles. Solar Energy. Photovoltaic Plates

\footnotetext{
${ }^{1}$ IFSP - Instituto Federal de Educação, Ciência e Tecnologia de São Paulo - Campus Piracicaba.

2 Engenheiro Mecânico (UNESP) com Mestrado e Doutorado em Engenharia de Produção pela Universidade Metodista de Piracicaba - UNIMEP. Possui os seguintes cursos complementares: Industry 4.0: How to Revolutionize your Business - Hong Kong Polytechnic University (2019-2020); Curso de Gestão de Inovação USP / VEDURA (1‥ Sem. 2018); Especialização em Melhoria Contínua (5S, Kaizen, Lean) no Japão - Nagoya (Jan. 2018) pela JICA - Japan International Cooperation Agency; Six Sigma Green Belt (Jan. 2017); qualificação em Project Management (PMI).
} 


\section{REVISTA CIENTÍFICA ACERTTE ISSN 2763-8928}

\section{INTRODUÇÃO}

Os assuntos sobre preservação ambiental, esgotamento do combustível fóssil e efeito estufa, estão sendo tratados como prioridades em diversos países, que estão buscando novas alternativas para diminuir as taxas de poluições. Diversas tecnologias estão sendo desenvolvidas e usadas para a substituição das fontes de energias não renováveis, para as fontes de energias renováveis, sendo a energia solar fotovoltaica um exemplo dos principais avanços utilizados atualmente. Esses processos de mudanças das últimas décadas, nas estruturas de energia, estão sendo reconhecidas como Transição Energética (WENCESLAO, 2017).

O carro elétrico surgiu nas primeiras décadas do século XIX na França e Inglaterra, teve seu desenvolvimento interrompido pela invenção dos motores à combustão e a descoberta de grandes reservas de petróleo no século XX (MOREIRA, 2013). A retomada no desenvolvimento de carros elétricos ocorre pela preocupação com o aumento do efeito estufa, com a preservação do meio ambiente e pelo esgotamento do combustível fóssil. Atualmente, os carros movidos por eletricidade são opções atrativas para o mercado, pois, de acordo com Baracho (2016), "Os Veículos Elétricos (VE's) são unidades energéticas que reúnem as modalidades de consumo, geração (pela frenagem regenerativa), armazenamento (conjunto de baterias) e, ainda, a de mobilidade". Além de haver projetos que demonstram a futura utilização do carro elétrico para a produção de energia elétrica, tem se tornado fonte de abastecimento da sua própria captação da energia solar e das residências. Esse fato é comprovado na tradução livre de Nissan (2016): "Com avanços em suas baterias de segunda vida, permitirá que os motoristas operem como "centros de energia" individuais capazes de armazenar, usar ou retornar energia limpa para a rede".

Nos dias atuais, existem três maneiras para que ocorra o carregamento de VE's. O mais comum se dá nas residências e empresas, que também é o mais lento, abastece as baterias em cerca de 6 a 8 horas. Outro meio é o carregador semirrápido, que são utilizados em espaços públicos e possuem uma duração de 1 a 2 horas. Já o rápido, que abastece em uma média de 15 a 30 minutos, $80 \%$ da capacidade da bateria e cerca de 1 hora para $100 \%$, ocorrem em eletropostos (24 Kwh) (CPFL, 2019 apud VILLALVA et al., 2020).

De acordo com Ferreira (2018) "Um ponto a ser observado é o fato de que a adoção de veículos elétricos, apenas será eficaz se a energia que abastece o carro vier de uma fonte não poluente". Caso a fonte energética seja uma poluidora, ou não renovável, os carros elétricos deixarão de serem opções tão atrativas para a diminuição de carbono na atmosfera, mas, se vier de uma fonte energética limpa, como a de células solares, energia que é bastante flexível, algo que possibilita o abastecimento em redes residenciais, possibilitando assim, um aumento na sustentabilidade mundial.

Os países necessitam de opções para a substituição de energia fóssil, as fontes de energias alternativas, como a solar, que é também, uma energia renovável, porém que possui alto preço no mercado. Além disso, também necessitam da substituição de carros movidos a motor de combustão, os carros elétricos podem ser a solução para este problema, pelo fato de utilizar um motor movido à 
ABASTECIMENTO DE CARROS ELÉTRICOS A PARTIR DA ENERGIA SOLAR Lucas Gomes Gélio, Francisco Ignácio Giocondo César

eletricidade. É importante ressaltar que, mesmo sendo tecnologias de alto custo, são desenvolvidas para a diminuição do efeito estufa e que ainda possuem dificuldades para atingir grande parcela dos consumidores. Para que haja o abastecimento dos carros elétricos, é utilizado em sua grande maioria, de sistemas centralizados, ocasionando na problemática da adoção em massa destes veículos. Para que ocorra a implantação da energia solar no sistema de abastecimento dos carros elétricos é necessária uma maior instalação de placas fotovoltaicas, para então viabilizar a descentralização de sua recarga, possibilitando os consumidores abastecer em suas próprias casas.

Esta pesquisa tem por objetivo estudar os meios de abastecimento de carros elétricos a partir da energia solar, observando as tecnologias envolvidas e as mais diversas formas de captação da energia solar, de forma a disponibilizar como energia elétrica. Tal estudo também irá identificar os impactos ambientais, energéticos e econômicos que a utilização da energia solar, para o abastecimento de carros elétricos, poderá proporcionar à sustentabilidade com a descentralização dos sistemas de recargas.

No capítulo dois, serão retratados dados de pesquisas relacionadas às palavras chaves: "Carros Elétricos", "Energia Solar", "Placas Fotovoltaicas". No terceiro capítulo será descrito a metodologia do qual foi desenvolvido este trabalho. No quarto capítulo ocorrerá o desenvolvimento da pesquisa proposta, com a finalidade de estudar a possível ocorrência da descentralização do abastecimento de carros elétricos, como é feito o abastecimento de veículos elétricos atualmente e a contribuição/viabilidade da utilização da energia solar em prol da sustentabilidade. No capítulo cinco ocorre a análise dos resultados obtidos nos capítulos anteriores e, por fim, no sexto, serão realizadas as considerações finais do estudo.

\section{REFERENCIAL TEÓRICO}

\subsection{Carros Elétricos}

No início do século XX, os VE's, carros movidos a vapor e os movidos à combustão, possuíam certa igualdade no mercado, especialistas daquela época acreditavam que os três pudessem coexistir, após cada um se encontrar nas áreas que melhor atuassem. Isso não ocorreu, principalmente pela produção em massa barata, de carros movidos a combustão interna, proporcionada por Henry Ford nos EUA, além do barateamento do petróleo e por possuírem o dobro da autonomia dos carros elétricos (MARTINS, 2015).

O efeito estufa se tornou alvo de diversas reuniões entre os países, fato este que é demonstrado com a 24를 Conferência das Nações Unidas sobre Mudanças Climáticas (COP 24), que ocorreu em Katowice, Polônia, as emissões de gases poluentes, principalmente o gás carbônico, são frutos, principalmente do setor do meio de transporte, sendo responsável por $25 \%$ de todos os gases de efeito estufa produzidos no mundo (AGÊNCIA BRASIL, 2018). A preocupação com o setor automobilístico trouxe novamente os veículos elétricos aos holofotes de desenvolvimento tecnológico. 


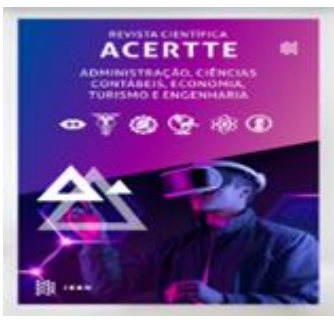

\section{REVISTA CIENTÍFICA ACERTTE ISSN 2763-8928}

ABASTECIMENTO DE CARROS ELÉTRICOS A PARTIR DA ENERGIA SOLAR Lucas Gomes Gélio, Francisco Ignácio Giocondo César

Figura 1: Esquema de funcionamento de um veículo elétrico

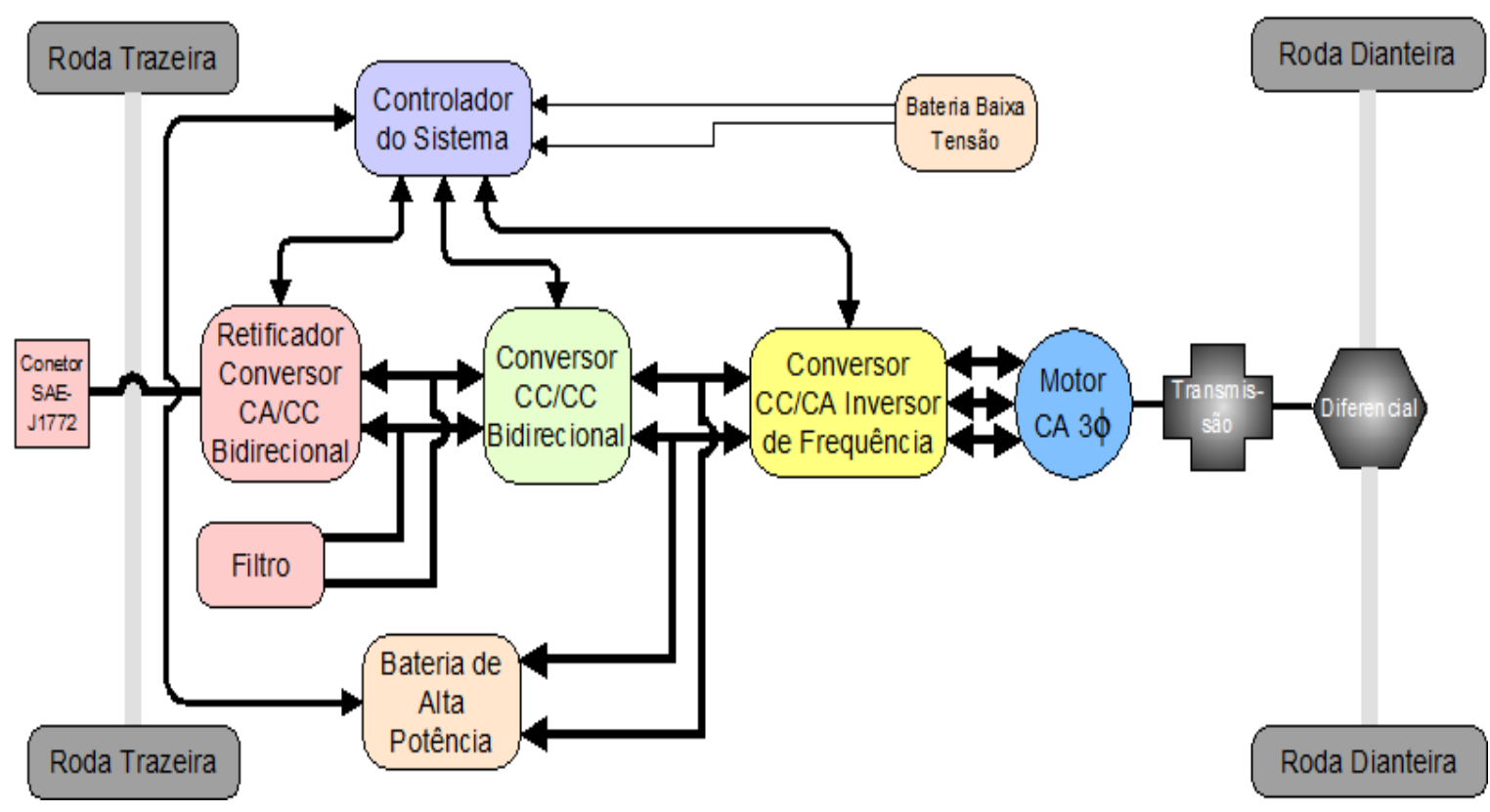

Fonte: Lenz (2013)

Os veículos elétricos possuem a função de tração e geração de movimento, convertendo energia elétrica em energia mecânica, utilizando unicamente motores elétricos, ou num sistema híbrido, onde há o complemento de outro motor no sistema. Por não utilizarem motores unicamente à combustão, seus níveis de poluição são menores. Porém, ainda que em uma escala menor, os VE's não estão isentos de ocasionar danos ambientais. O descarte de suas baterias em locais impróprios causa problemas ecológicos, devido ao uso de metais pesados na sua composição. Outro desafio dos carros elétricos são as fontes energéticas que os abastecem, pois mesmo que as baterias estejam dentro dos protocolos de segurança sustentável, ainda ocorrerão lesões ao meio ambiente, caso utilizem de energias não limpas (AZEVEDO, 2018).

\subsection{Energia Solar}

Desde o início da humanidade o Sol tem sido de suma importância para a evolução tecnológica, este papel atualmente é evidenciado no desempenho da expansão da matriz energética mundial. Sendo uma energia limpa, flexível e renovável, ela acaba por proporcionar a diversificação de fontes, na substituição do uso de combustíveis fósseis e a exploração de possibilidades para sua utilização no auxílio da preservação do meio ambiente (ATLAS BRASILEIRO DE ENERGIA SOLAR, 2017, apud PEZERICO, 2020). A utilização da energia solar para o abastecimento de carros elétricos é uma forma de potencializar e garantir o baixo impacto ao meio ambiente, trazendo opções para diminuir ainda mais as poluições paralelas à energia utilizada nos VE's. 


\section{REVISTA CIENTÍFICA ACERTTE} ISSN 2763-8928

\subsection{Placas Fotovoltaicas}

Para Ferreira (2018) "A conversão da energia solar em energia elétrica, depende de sistemas fotovoltaicos, projetados a partir de células fotovoltaicas, que produzem energia de acordo com a radiação solar incidente." Para a produção de energia elétrica a partir da energia solar, o sistema comumente utilizado é o fotovoltaico, pois é feita de materiais semicondutores, possibilitando que seus átomos colidam com as partículas da luz do Sol, gerando a corrente com o deslocamento dos elétrons (AZEVEDO, 2018). Para Machado e Miranda (2015) as tecnologias utilizadas para as placas solares fotovoltaicas atuais são: "Células de silício, das quais existem três tipos. Podem ser de silício cristalino (c-Si), que se subdividem em monocristalino e policristalino, ou podem ser de silício amorfo".

Para que haja a conversão da energia solar em energia elétrica, é necessário que as placas fotovoltaicas recebam a radiação solar, que é responsável por aquecer as placas e um fluido que se encontra no interior dos tubos e circula todo o sistema devido a correntes de convecção, percorrendo um circuito fechado, sendo muitas vezes um sistema de bombeamento. Já o tubo, costumeiramente de cobre, adentra num reservatório de água, que é aquecida por transferência de calor. O aquecimento da placa, tubo, fluido e da água, ocorre através da condução de energia térmica, proveniente da luz solar (MARINHO NETO et al, 2010)

Em carros elétricos as células solares possuem funções semelhantes às instaladas em casas, convertendo a energia potencial em energia elétrica, este fato fica evidenciado no trecho de Bloomberg (2018) apud Cruz e Sorrentino (2018) "A função dos painéis fotovoltaicos é a conversão da energia solar em energia elétrica que será posteriormente condicionada para ser devidamente utilizada por máquinas elétricas capazes de induzir movimento ao veículo".

\section{MÉTODO \& METODOLOGIA}

A pesquisa foi desenvolvida a partir de um levantamento bibliográfico exploratório, utilizando das principais bases de dados, como Web of Science e o Google Acadêmico, entre outros.

A metodologia adotada neste trabalho foi de natureza exploratória, pois tem como objetivo gerar conhecimentos teóricos acerca de problemas específicos. Com relação à forma de abordagem é uma pesquisa qualitativa, pois o estudo não requereu o uso de métodos estatísticos, mas sim a busca de fontes para coletas de dados, onde o pesquisador foi instrumento chave para isto. Com relação aos objetivos, foi uma pesquisa exploratória, pois buscou uma maior familiaridade com o tema para torná-lo mais explícito, como também, envolveu levantamento bibliográfico, pois teve a forma de uma pesquisa bibliográfica e documental.

\section{PESQUISA}

Os primeiros carros elétricos datam das primeiras décadas do século XIX (MOREIRA, 2013). Os VE's possuíam uma maior procura no mercado consumidor, por oferecerem um maior conforto 


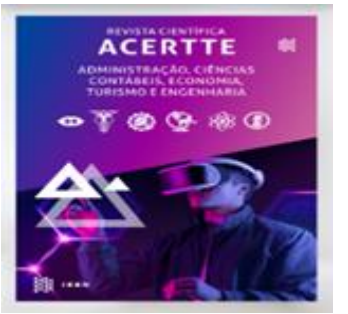

\section{REVISTA CIENTÍFICA ACERTTE ISSN 2763-8928}

aos passageiros, por não ter ruído ou cheiro algum e por deter uma operação mais simplificada do que em comparação aos carros movidos à combustão interna (BARACHO, 2016). Baran e Legey (2010) demonstram, a partir dos dados de DOE (2009), que o sistema de produção em série de automóveis, desenvolvidos por Henry Ford, diminuiu o preço final dos carros movidos à combustão, houve também a criação do sistema de partida elétrica para tais veículos, somado à descoberta de uma grande reserva de petróleo no Texas e por fim, grandes rodovias que demandavam veículos que pudessem percorrer maiores distâncias, foram os principais causadores do crescimento dos carros movidos por motores à combustão, fato que ocasionou o grande declínio na produção, compra e venda de VE's. Baran e Legey (2010) complementam dizendo que "Houve diversas iniciativas de trazê-los de volta ao mercado no período, mas nem os automóveis elétricos puros, nem os híbridos, estavam aptos a competir no mercado com os automóveis convencionais"

Figura 2: Evolução Histórica dos Veículos Elétricos

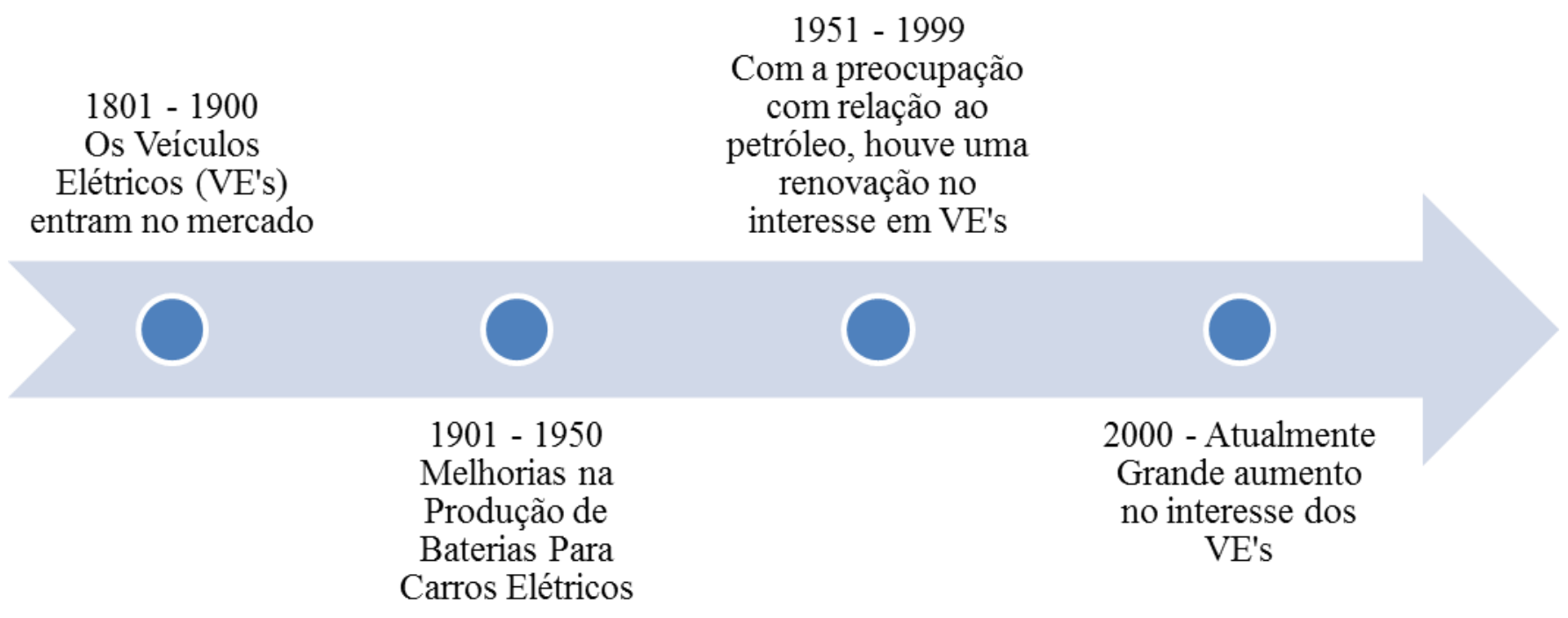

Fonte: Adaptação de Kar et al., (2013)

Nos anos de 1960 a população começou a olhar novamente para os veículos elétricos, devido ao fato de que os automóveis eram as principais fontes de poluição do meio ambiente. Em 1970 essa preocupação ficou ainda mais evidenciada com o livro "Limites para o Crescimento", publicado em 1972 pelo Clube de Roma e também com a crise do petróleo em 1973. No fim dos anos de 1980, os VE's receberam uma maior atenção, atrelados à preocupação ambiental, assim como na década anterior. Já em 1990 foram vistos movimentos claros do início da retomada com tal tecnologia na Califórnia, as primeiras normas para uma regulação de emissão zero de gases poluentes. No ano de 1992 a Agenda 21 e estratégias da União Europeia para uma mobilidade sustentável, acabaram se tornando grandes expoentes da necessidade da redução do uso de energia fóssil e aumento nos desenvolvimentos de fontes renováveis e limpas (BARAN; LEGEY, 2010). 


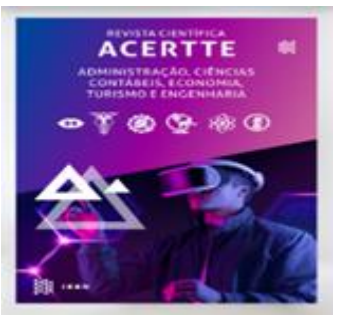

Para Kleina (2021) “Já em 2004 foi fundada a Tesla Motors, que gerou um clima de startup e investimentos de risco no estilo Vale do Silício para o mercado de carros elétricos. O primeiro modelo anunciado foi o Roadster, que iniciou a produção só em 2008". As melhorias tecnológicas nas baterias influenciaram na retomada da produção de carros elétricos e de carros híbridos. De acordo com Noce (2009) "A bateria de NiMH foi a primeira bateria utilizada em larga escala após a de chumbo ácido para aplicações tracionárias." Ele também completa dizendo que o EV1 General Motors, um carro elétrico, Toyota Prius e Honda Insight, veículos híbridos, utilizam de tal bateria.

Para Silva (2019) "É uma máquina que transforma a potência elétrica em potência mecânica, com reduzida porcentagem de perdas. Quando o motor elétrico é ligado, ele absorve certa quantidade de energia elétrica e a transforma em torque". Essa energia elétrica é armazenada em baterias inseridas nos veículos, e para Castro e Ferreira (2010) "O desenvolvimento das baterias foi fundamental para viabilizar o ressurgimento dos veículos elétricos. Esse desenvolvimento ocorreu na esteira do rápido avanço dos setores de informática e telecomunicações na década de 1990". No quadro (1) abaixo, é possível observar os tipos de baterias que mais são utilizadas atualmente no mercado.

Quadro 1: Baterias recarregáveis comumente utilizadas em carros elétricos

\begin{tabular}{|c|c|c|c|c|c|}
\hline Baterias & Aplicações típicas & $\begin{array}{c}\text { Descarga } \\
\text { automática } \\
(\%)\end{array}$ & $\begin{array}{c}\text { Tensão } \\
\text { Nominal da } \\
\text { célula (V) }\end{array}$ & $\begin{array}{c}\text { Energia } \\
\text { Específica } \\
\text { (Wh/Kg) }\end{array}$ & $\begin{array}{c}\text { Densidade } \\
\text { de Energia } \\
\text { (Wh/l) }\end{array}$ \\
\hline $\begin{array}{c}\text { Chumbo } \\
\text {-ácido }\end{array}$ & $\begin{array}{c}\text { Submarinos, automóveis, EVs, cadeiras de } \\
\text { rodas, scooteres, e-bikes e unidades UPS. }\end{array}$ & $2 \%$ & 2,1 & $20-35$ & $54-95$ \\
\hline NiMH & $\begin{array}{c}\text { EVs, HEVs, locomotivas, computadores } \\
\text { portáteis, telemóveis, aparelhos elétricos, } \\
\text { instrumentos e equipamentos médicos. }\end{array}$ & $5 \%$ & 1,2 & 65 & 150 \\
\hline Li-ion & $\begin{array}{c}\text { EVs, computadores portáteis, telemóveis, } \\
\text { máquinas fotográficas, aparelhos rádio } \\
\text { modelismo e MP3. }\end{array}$ & $10 \% /$ Mês & 3,5 & 140 & $250-620$ \\
\hline
\end{tabular}

Fonte: Adaptação de Freitas (2012) e Denton (2018) apud Stahelin e Pauli (2021)

As baterias de chumbo-ácido são usualmente utilizadas em veículos com o propósito de alimentar os sistemas de partida, iluminação e ignição. É uma bateria agressiva ao meio ambiente, já que os metais pesados utilizados em sua composição necessitam de uma recuperação para a produção de novos exemplares, muitas vezes ocorre utilizando o processo pirometalúrgico que 


\section{REVISTA CIENTÍFICA ACERTTE} ISSN 2763-8928

ABASTECIMENTO DE CARROS ELÉTRICOS A PARTIR DA ENERGIA SOLAR Lucas Gomes Gélio, Francisco Ignácio Giocondo César

contamina a atmosfera com gases poluentes e caso seja feito o descarte incorreto, pode acarretar na poluição de solos e de aquíferos subterrâneos (BOCCHI; FERRACIN; BIAGGIO, 2000).

Para Azevedo (2018) "A bateria níquel-hidreto metálico (NiHM) possui uma liga metálica com alta capacidade de armazenamento de hidrogênio que proporciona alta densidade de energia e alta capacidade da bateria." Suas principais vantagens com relação a outras baterias são a sua reciclagem lucrativa por causa do níquel, pouco material tóxico e por seu armazenamento e transporte simples. Já suas desvantagens são refletidas em sua baixa vida útil, uma elevada autodescarga, seu rendimento e desempenho são reduzidos durante a recarga rápida por produzir calor e por não tolerar sobrecarga (FREITAS, 2012).

O li-ion é o expoente de um grande avanço tecnológico para os VE's e possui diversos gêneros que derivam de si, atualmente se destacando a $\mathrm{LiFePO}_{4}$. Suas principais diferenças são encontradas nos materiais utilizados no cátodo, porém, atualmente, estão sendo empregados os usos de modificações e substituições do grafite que é utilizado comumente. Em altas temperaturas, essas baterias acabam tendo uma perda de desempenho e de segurança, além de não possuir uma alta durabilidade. Mesmo que não possuam um bom custo total, ainda possuem vantagens em compactação com as baterias de $\mathrm{NiMH}$, possuindo um maior volume, eficiência e a utilização de metal mais barato. Em comparação com a de chumbo, possui uma baixa toxicidade e atualmente são grandes apostas para os carros elétricos e híbridos (FREITAS, 2012; CASTRO; FERREIRA, 2010; AZEVEDO, 2018).

Nos dias de hoje, existem duas maneiras de realizar o abastecimento de carros elétricos, sendo por recarga indutiva e recarga condutiva. Baracho (2016) afirma que "A primeira necessita de uma estação de carga onde uma bobina é utilizada para criar o fluxo magnético alternado que induz corrente em uma segunda bobina embarcada no dispositivo a ser carregado". E completa seu raciocínio dizendo que "A recarga condutiva é feita por meio do contato físico, podendo ser realizadas em tomadas padrões ou em estações de recarga" Dentre essas duas maneiras de carregamento são possíveis ainda obter quatro modos diferentes previstos pela norma ABNT NBR 61851:2013, que estão representados no quadro (2) abaixo. 
ABASTECIMENTO DE CARROS ELÉTRICOS A PARTIR DA ENERGIA SOLAR Lucas Gomes Gélio, Francisco Ignácio Giocondo César

Quadro 2: Tipos de carga previstos pela norma ABNT NBR 61851:2013

\begin{tabular}{|c|c|c|c|c|}
\hline Modos & Descrição & Tensão (V) & \multicolumn{2}{|c|}{ Corrente (A) } \\
\hline \multirow{2}{*}{ Modo 1} & \multirow{2}{*}{$\begin{array}{l}\text { Carga lenta através de uma tomada } \\
\text { residencial }\end{array}$} & \multirow{2}{*}{$\begin{array}{l}250 \\
480\end{array}$} & Monofásico & \multirow{2}{*}{$\begin{array}{l}16 \\
\mathrm{CA}\end{array}$} \\
\hline & & & Trifásico & \\
\hline \multirow{2}{*}{ Modo 2} & \multirow{2}{*}{$\begin{array}{l}\text { Carga lenta através de uma tomada } \\
\text { residencial com dispositivo interno de } \\
\text { proteção }\end{array}$} & \multirow{2}{*}{$\begin{array}{l}250 \\
480\end{array}$} & Monofásico & \multirow{2}{*}{$\begin{array}{l}32 \\
\mathrm{CA}\end{array}$} \\
\hline & & & Trifásico & \\
\hline \multirow{2}{*}{ Modo 3} & \multirow{2}{*}{$\begin{array}{l}\text { Carga lenta ou rápida através de um } \\
\text { ponto específico para VE's com } \\
\text { sistemas de controle e proteção }\end{array}$} & & Monofásico & $\begin{array}{l}32 \\
\mathrm{CA}\end{array}$ \\
\hline & & & Trifásico & $\begin{array}{l}250 \\
C A\end{array}$ \\
\hline \multirow{2}{*}{ Modo 4} & \multirow{2}{*}{$\begin{array}{c}\text { Carga rápida usando um carregador } \\
\text { externo }\end{array}$} & & Monofásico & \multirow{2}{*}{$\begin{array}{l}400 \\
\mathrm{CC}\end{array}$} \\
\hline & & & Trifásico & \\
\hline
\end{tabular}

Fonte: Adaptação de Valle (2015)

Vale citar que há também os supercharger's da montadora Tesla, que recarregam as baterias do veículo "Model $S$ " em apenas uma hora, sendo extremamente rápidos em comparação com outros métodos utilizados (ANTUNES, 2018).

Os motores elétricos possuem algumas vantagens em comparação com os carros que utilizam de combustíveis fósseis para seu abastecimento, uma delas é o valor de manutenção ser menor, outro fato é a sua eficiência que pode ultrapassar a marca dos $90 \%$, enquanto os outros veículos a combustão não chegam a $30 \%$. Isso é um fato do qual demonstra uma maior economia aos bolsos da sociedade. Com o quadro (3) a seguir, fica evidenciada sua economia média (FERREIRA, 2012). 


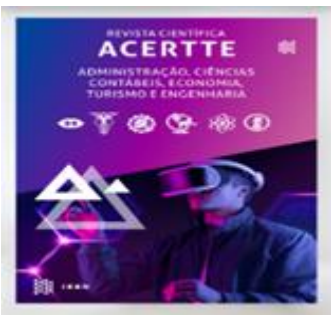

\section{REVISTA CIENTÍFICA ACERTTE ISSN 2763-8928}

Quadro 3: Comparação de custeio entre um carro elétrico e um carro tradicional

\begin{tabular}{|c|c|c|c|}
\hline \multicolumn{2}{|c|}{ Carro Elétrico } & \multicolumn{2}{c|}{ Carro Tradicional } \\
\hline $\mathrm{Km} /$ dia & 50 & $\mathrm{Km} /$ dia & 50 \\
\hline $\mathrm{Km} / \mathrm{mês}$ & 1550 & $\mathrm{Km} / \mathrm{mês}$ & 1550 \\
\hline $\mathrm{kWh} / \mathrm{Km}$ & 0,18 & $\mathrm{Km} / \mathrm{l}$ & 11 \\
\hline Energia $(\mathrm{kWh})$ & 279 & Litros & 136,36 \\
\hline Custo do kWh (R\$) & 0,35 & Custo Combustível (R\$) & 2,5 \\
\hline Custo Mensal (R\$) & 97,65 & Custo Mensal (R\$) & 240,91 \\
\hline Custo por Km (R\$) & 0,063 & Custo por Km (R\$) & 0,23 \\
\hline
\end{tabular}

Fonte: Adaptação de Ferreira (2012)

Com o avanço tecnológico, investimento e políticas para a facilitação do uso de energia solar para o carregamento de carros elétricos, são possíveis notar na diminuição de valores pagos por quilômetros rodados, em 2019 o valor alcançou $R \$ 0,06$. No mesmo ano, o abastecimento de veículos a combustível fóssil, era cerca de $R \$ 0,40$ por quilômetros rodados. Ainda que haja tais incentivos, o valor de aquisição de um veículo elétrico ainda é mais caro, sendo apenas questão de tempo para que ocorra uma maior acessibilidade monetária ao público. (COMITÊ BRASILEIRO DA CIER - BRACIER, 2019 apud STAHELIN; PAULI, 2021). Esse interesse na compra de veículos elétricos tem aumentado conforme o tempo passa e, cada vez mais a população se aproxima da obtenção deles, aumentando a procura do mercado para este ramo e de acordo com Kleina (2021) "Em 2017, a venda anual de carros elétricos superou a barreira de 1 milhão de unidades pela primeira vez".

A partir da eficiência dos VE's, casas com células de energia solar, iniciativas sustentáveis e evoluções das tecnologias verdes, muitos países perceberam que o uso de energias limpas e renováveis são algumas das principais ferramentas para o combate à degradação do meio ambiente. O Brasil, como exemplo, sancionou leis e projetos que buscam auxiliar no desenvolvimento e na implantação dessas tecnologias. Isso é evidenciado nas palavras de Silva (2019):

Em 17 de abril de 2012, entrou em vigor a resolução normativa da Agência Nacional de Energia Elétrica - ANEEL № 482/2012, a qual estabelece que o consumidor brasileiro pode gerar sua própria energia elétrica a partir de fontes renováveis ou cogeração qualificada, e fornecer o excedente da energia produzida a rede elétrica a qual estiver conectado, colaborando com o desempenho da rede, ou seja, trata-se da micro e da minigeração distribuídas de energia elétrica. Com o objetivo de reduzir os custos e tempo para a conexão da microgeração e minigeração, aumentando o público-alvo, e melhorando as informações na fatura. 


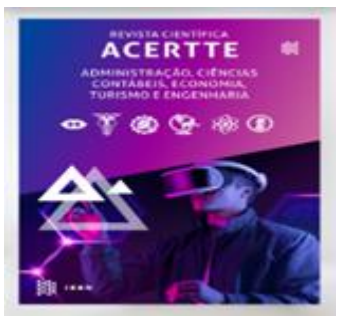

\section{REVISTA CIENTÍFICA ACERTTE ISSN 2763-8928}

ABASTECIMENTO DE CARROS ELÉTRICOS A PARTIR DA ENERGIA SOLAR Lucas Gomes Gélio, Francisco Ignácio Giocondo César

Assim, as pessoas podem se movimentar por suas cidades utilizando de tecnologias limpas, enquanto produzem sua própria energia elétrica para o dia a dia, além de gerar também uma economia para si e colaborando ainda mais com o meio ambiente. Com o aumento na instalação de placas fotovoltaicas e redes inteligentes, será possível a criação de micro produtores de energia, tanto com a energia solar, como com os carros elétricos, resultando na redução da demanda energética oriundos das usinas produtoras de energias não renováveis (FERREIRA, 2012). Também surgirão novas oportunidades de negócio e empregos acarretados pelo desenvolvimento tecnológico, isso fica evidenciado na figura (3) abaixo.

Figura 3: Nova cadeia de valores dos VE's

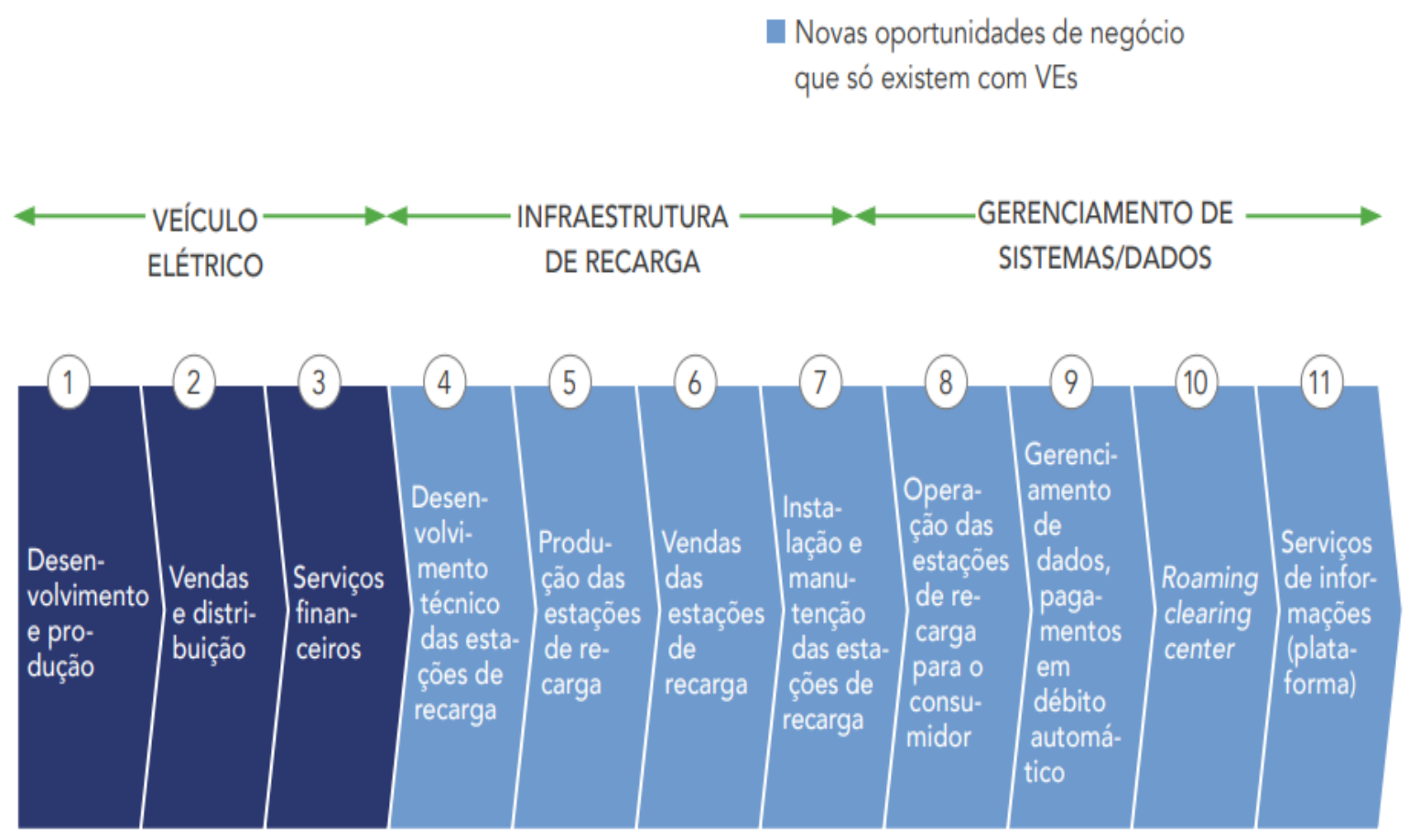

Fonte: Amsterdam Round Tables \& McKinsey \& Company (2014)

Para Cardoso (2018) "Com uma maior quantidade de veículos híbridos e elétricos circulantes, se estima que ocorra um aumento na oferta de cursos e especializações para preparar novos e antigos profissionais da área". Fato este que comprova os benefícios para a sociedade.

Países atualmente estão discutindo datas futuras para o banimento de carros movidos à combustão ou metas para diminuir a venda de veículos movidos a combustão, a ponto de não os venderem mais futuramente. Em Costa et al. (2017) vemos alguns países com estes objetivos: "Noruega (meta de vender apenas carros elétricos após 2025), Alemanha (banir veículos à combustão interna - VCls - após 2030) e Índia (também banir VCls após 2030)". Mesmo com certa descrença dessas metas, isso demonstra que políticas públicas e movimentos estão sendo desenvolvidos em prol de um futuro do qual haverá menos carbono produzido pelos veículos. $O$ 
interesse para que isso ocorra é demonstrado no quadro (4) a seguir, que evidencia o aumento de compra de estoque por parte de diversos países em 2020, mostrando que naquelas localidades, estão havendo investimentos e um aumento na meta para a difusão de veículos elétricos.

Quadro 4: Metas de estoque de carros elétricos até 2020 para alguns países

\begin{tabular}{|c|c|c|c|c|}
\hline $\begin{array}{c}\text { Países que } \\
\text { anunciaram metas até } \\
2020 \text { ou mais tarde }\end{array}$ & $\begin{array}{l}\text { Estoque de VEs } \\
\text { em } 2015 \text { (mil } \\
\text { veículos) }\end{array}$ & $\begin{array}{l}\text { Meta do estoque } \\
\text { de VEs em } 2020\end{array}$ & $\begin{array}{l}\text { Participação dos VEs } \\
\text { na venda de carros } \\
\text { entre } 2016 \text { e } 2020\end{array}$ & $\begin{array}{l}\text { Participação } \\
\text { dos VEs no } \\
\text { estoque total } \\
\text { em } 2020\end{array}$ \\
\hline Áustria & 5,3 & 0,2 & $13 \%$ & $4 \%$ \\
\hline China & 312,3 & 4,5 & $6 \%$ & $3 \%$ \\
\hline Dinamarca & 8,1 & 0,2 & $23 \%$ & $9 \%$ \\
\hline França & 54,3 & 2,0 & $20 \%$ & $6 \%$ \\
\hline Alemanha & 49,2 & 1,0 & $6 \%$ & $2 \%$ \\
\hline Índia & 6,0 & 0,3 & $2 \%$ & $1 \%$ \\
\hline Japão & 126,4 & 1,0 & $4 \%$ & $2 \%$ \\
\hline Holanda & 87,5 & 0,3 & $10 \%$ & $4 \%$ \\
\hline Portugal & 2,0 & 0,2 & $22 \%$ & $5 \%$ \\
\hline Reino Unido & 49,7 & 1,5 & $14 \%$ & $5 \%$ \\
\hline EUA & 101,0 & 1,2 & $6 \%$ & $2 \%$ \\
\hline
\end{tabular}

Fonte: Global EV Outlook, IEA, (2016)

\section{ANÁLISE DOS RESULTADOS}

Para que os carros elétricos se tornem não somente uma alternativa interessante, mas uma alternativa importante e possível, é preciso que haja o desenvolvimento de movimentos não governamentais e de políticas de incentivo. É possível analisar que existem algumas barreiras que dificultam a consolidação dos VE's no mercado, sendo a falta de incentivo, barreiras mercadológicas, institucionais e políticas, os maiores expoentes que contrapõem a necessidade da substituição dos combustíveis fósseis e diversas questões ambientais que colocam esses veículos em posição capaz de resolver tais problemáticas. (BARAN; LEGEY, 2010). Isso é demonstrado no trecho de Azevedo (2018) "O patamar do petróleo ainda é uma barreira para fontes alternativas e o imediatismo ainda tem grande influência no consumo humano". Ferreira (2012) complementa "o maior desafio para a 


\section{REVISTA CIENTÍFICA ACERTTE} ISSN 2763-8928

adoção de VE se deve ao seu preço: a carga tributária é alta ao se considerar o total dos impostos federais (IPI) e estaduais (ICMS e IPVA)".

Para Baran e Legey (2010) "É importante notar que, mesmo nos casos em que a eletricidade é gerada a partir de combustíveis fósseis, como o carvão e o gás natural, o carro elétrico traz a vantagem de concentrar as emissões nas fontes geradoras de energia". Este fator comprova, ainda mais, que mesmo com diversas barreiras e problemas no caminho dos veículos elétricos, ainda é notável sua importância para a sociedade. Freitas (2012) complementa "Assiste-se a uma grande movimentação dos fabricantes de automóveis (que se nota pelo investimento, investigação e exibição de protótipos) e a grandes debates políticos, ambientais e tecnológicos". E com tais interesses de desenvolvimento, é fácil perceber o futuro ainda mais promissor dos carros elétricos, sendo abastecidos por energia solar como forma de evolução tecnológica, corroborando ainda mais com o aumento da instalação das placas fotovoltaicas nas residências e edifícios públicos e privados.

\section{CONSIDERAÇÕES FINAIS}

Durante o artigo foi proposto o estudo a partir de um levantamento bibliográfico exploratório, com o objetivo de estudar os meios de abastecimento de carros elétricos a partir da energia solar, observando as tecnologias envolvidas e as mais diversas formas de captação da energia solar de forma a disponibilizar como energia elétrica. Conforme as pesquisas apresentadas, são perceptíveis às relações entre os VE's e a energia solar, que se dão na melhoria da tecnologia, da preservação ambiental, diminuição da poluição pelos gases estufa, a descentralização da energia de abastecimento de residências e veículos elétricos, além de também proporcionar novos meios de rendimento para a economia pública.

Infelizmente existem barreiras que dificultam a difusão dos carros elétricos para a população, sendo principalmente refletidos no, ainda, uso de combustíveis fósseis e carros a combustão interna, no descarte incorreto de suas baterias, na utilização de baterias com deficiência de captação energética, em barreiras mercadológicas que se refletem no alto valor de compra do sistema para o abastecimento de carros elétricos a partir da energia solar. $\mathrm{O}$ baixo incentivo de alguns países para 0 desenvolvimento de novas tecnologias que corroborem com a sua implementação e mesmo que haja a compra de um VE, o sistema da rede de energia pode não ser abastecido por uma energia não renovável e não limpa, diminuindo a eficiência ambiental que poderia ser adquirida através da recarga por um sistema que utilize de células fotovoltaicas. Além de barreiras decorrentes de determinadas políticas adotadas por alguns países que focam no imediatismo do uso de combustíveis derivados do petróleo.

Mesmo que haja tais barreiras, os carros elétricos e a energia fotovoltaica estão cada vez mais se correlacionando a partir de novas tecnologias, políticas de incentivos e movimentos que corroboram na melhoria, instalação e utilização de energia solar para a recarga de carros elétricos. Com a preocupação a partir do acelerado aquecimento global, diversas empresas também deram mais atenção a esta situação, voltando-se cada vez mais para um mercado de viabilização de 


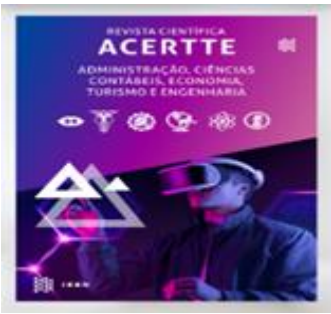

instalação e utilização dos dois elementos em conjuntos, sendo evidenciados, como por exemplo, em eletro postos, residências e edifícios que utilizam de energia solar para o abastecimento de carros elétricos, dando uma maior liberdade para os donos e descentralizando seu abastecimento, e até mesmo em tecnologias mais atuais, onde os veículos possuem suas próprias maneiras de produção de energia, utilizando do Sol, mantendo em baterias menos poluidoras e devolvendo para a rede elétrica. Todos esses fatores corroboram para a evolução tecnológica, pois se o mercado consumidor possui um aumento no interesse desses sistemas, mais investimento terá, resultando em melhorias e pesquisas mais aprofundas, além de auxiliar na sustentabilidade social, econômica e ambiental de países que facilitam e adotam a utilização de sistemas de abastecimento de carros elétricos a partir da energia solar.

\section{REFERÊNCIAS}

AZEVEDO, M. H. Carros Elétricos: viabilidade econômica e ambiental de inserção competitiva no mercado brasileiro. 2018. 54 f. Monografia (Graduação em Engenharia de Controle e Automação) Universidade Federal de Ouro Preto - UFOP, Ouro Preto, 2018. Disponível em: https://monografias.ufop.br/handle/35400000/1579. Acesso em: 13 ago. 2021.

ANTUNES, P. D. R. Veículos elétricos, funcionamento e seus benefícios. 2018. TCC (Graduação) - Centro Universitário UNIFACVEST, Lages, SC, 2018. Disponível em: https://www.unifacvest.edu.br/assets/uploads/files/arquivos/d74d7-antunes,-p.-d.-r.-veicculoseletricos-funcionamento-e-seus-beneficios.-tcc,-2018..pdf. Acesso em: 30 jul. 2021.

BARACHO, G. M. M. O. Veículos Elétricos: estudo preliminar das estratégias de suprimento de energia por eletroposto solar fotovoltaico. 2016. TCC (Graduação) - Universidade de Brasília UnB, Faculdade UnB Gama - FGA, Gama, DF, 2016. Disponível em: https://bdm.unb.br/bitstream/10483/15088/1/2016 GabrielleMoniqueBaracho.pdf Acesso em: 31 jul. 2021.

BARAN, R.; LEGEY. L. F. L. Veículos Elétricos: história e perspectivas no Brasil. In.: XIII Congresso Brasileiro de Energia (novembro de 2010). Rio de Janeiro: BNDES, 2010. Disponível em: https://web.bndes.gov.br/bib/ispui/handle/1408/1489. Acesso em: 09 ago. 2021.

BIAGGIO, S. R.; BOCCHI, N.; FERRACIN, L. C. Pilhas e Baterias: funcionamento e impacto ambiental. Química Nova Escola, n. 11, maio. 2000. Disponível em: http://anesc.sbq.org.br/online/qnesc11/v11a01.pdf. Acesso em: 20 ago. 2021.

BRITO, D. Efeito Estufa: transporte responde por 25\% das emissões globais. Agência Brasil, 2018. Disponível em: https://agenciabrasil.ebc.com.br/geral/noticia/2018-12/efeito-estufa-transporteresponde-por-25-das-emissoes-globais. Acesso em: 05 ago. 2021.

CARDOSO, J. P. R. Avaliação do impacto socioambiental da adoção do carro elétrico no Brasil. 2018. TCC (Graduação) - Universidade Federal de Santa Catarina, Araranguá, 2018. Disponível em: https://repositorio.ufsc.br/handle/123456789/187694 Acesso em: 29 ago. 2021.

COSTA, J. E. G.; DELGADO, F.; FEBRARO, J.; SILVA, T. B. Carros Elétricos. Cadernos FGV ENERGIA, ano 4, $\mathrm{n}$. 7, maio. 2017 Disponível em: 


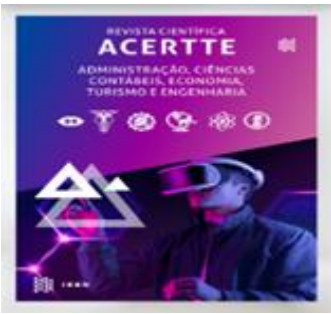

https://bibliotecadigital.fgv.br/dspace/bitstream/handle/10438/19179/Caderno\%20Carros\%20EletricosFGV-BOOK\%20VFINAL.pdf Acesso em: 25 ago. 2021.

FERREIRA, F. B. A evolução automobilística e aplicação de Smart Grid para utilização de energia renovável. 2012. TCC (Graduação) - Universidade São Francisco, Itatiba, 2012. Disponível em: http://lyceumonline.usf.edu.br/salavirtual/documentos/2324.pdf. Acesso em: 30 ago. 2021.

FERREIRA, R. T. Planejamento do carregamento de veículos elétricos atendidos por um eletroposto isolado. 2018. Dissertação (Mestrado) - Universidade Federal do Espírito Santo, Vitória, ES, 2018. Disponível em: http://repositorio.ufes.br/handle/10/10918 Acesso em: 22 ago. 2021.

FREITAS, J. C. N. Projeto e análise ao funcionamento de carros elétricos. 2012. Dissertação (Mestrado) - Universidade do Minho, 2012. Disponível em: http://repositorium.uminho.pt/handle/1822/22557 Acesso em: 20 ago. 2021.

KAR, N. C.; IYER, K. L. V.; LABAK, A.; XIAOMIN, LU; CHUNYAN, LAI; BALAMURALI, A.; ESTEBAN, B.; SID AHMED, M. Courting and Sparking: Wooing consumers? Interest in the EV Market. IEEE Electrification Magazine, v. 1, n. 1, sep. 2013. Disponível em: https://www.researchgate.net/publication/260712282 Courting and Sparking Wooing Consumers I nterest in the EV Market Acesso: 09 ago. 2021.

KLEINA, N. A História dos Carros Elétricos. Tecmundo, 2021 Disponível em: https://www.tecmundo.com.br/mobilidade-urbana-smart-cities/212835-historia-carros-eletricos-saibatudo-comecou.htm Acesso em: 10 ago. 2021.

LENZ, A. L. 0 básico sobre o sistema de tração de veículos elétricos. [S. l.: S. n.], 2013. Disponível em: http://automoveiseletricos.blogspot.com/2013/03/o-basico-sobre-sistema-de-tracaode.html Acesso em: 15 ago. 2021.

MACHADO, C. T.; MIRANDA, F. S. Energia Solar Fotovoltaica: uma breve revisão. Revista Virtual de Química, v. 7, n. 1, 2015. Disponível em: https://rvq-sub.sbq.org.br/index.php/rvq/article/view/664. Acesso em: 16 ago. 2021.

MACHADO, G. M. V.; PRYM, G. C. S.; VARGAS, T. N.; VILLALVA M. G. Revisão de Sistemas de Carregamento Para Veículos Elétricos Utilizando Sistemas Fotovoltaicos. In.: VIII Congresso Brasileiro de Energia Solar - Fortaleza, 2020. Disponível em: https://anaiscbens.emnuvens.com.br/cbens/article/view/1027/1027. Acesso: 03 ago. 2021.

MARINHO NETO, A. B.; NUNES, G. B.; SILVA, M. A. Uso de painéis solares e sua contribuição para a preservação do meio ambiente. Bolsista de Valor, v. 1, 2010. Disponível em: https://essentiaeditora.iff.edu.br/index.php/BolsistaDeValor/article/view/4706. Acesso em: 11 ago. 2021.

MARTINS, C. N. Ações necessárias rumo a uma nova rota tecnológica: o carro elétrico. Com Ciência, nov. $2015 . \quad$ Disponível em: https://www.comciencia.br/comciencia/index.php?section=8\&edicao=118\&id=1424\&tipo=1. Acesso: 15 ago. 2021.

MOREIRA, D. A. M. Posto de carregamento de veículos eléctricos com painel fotovoltaico, sistema de armazenamento e ligação à rede eléctrica. 2013. Dissertação (Mestrado) - Instituto Técnico Lisboa, Lisboa, 2013.2 Disponível em: https://fenix.tecnico.ulisboa.pt/downloadFile/395146019194/dissertacao.pdf Acesso: 04 ago. 2021. 


\section{REVISTA CIENTÍFICA ACERTTE} ISSN 2763-8928

ABASTECIMENTO DE CARROS ELÉTRICOS A PARTIR DA ENERGIA SOLAR Lucas Gomes Gélio, Francisco Ignácio Giocondo César

NISSAN MOTOR CORPORATION. Introducing the fuel station of the future. [S. I.]: Nissan, 2016. Disponível em: https://reports.nissan-global.com/EN/?p=17513 Acesso: 06 ago. 2021.

NOCE, T. Estudo do funcionamento de veículos elétricos e contribuições ao seu aperfeiçoamento. 2009. Dissertação (Mestrado) - Pontifícia Universidade Católica de Minas Gerais, Belo Horizonte, MG, 2009.2 Disponível em: http://www.biblioteca.pucminas.br/teses/EngMecanica NoceT 1.pdf Acesso em: 10 ago. 2021.

PEZERICO, V. N. O. Estudo comparativo para carregamento de carros elétricos através de geração distribuída e análise econômica. 2020. TCC (Bacharel em Engenharia elétrica) Universidade Federal de Santa Maria, Santa Maria, RS, 2020. Disponível em: https://repositorio.ufsm.br/bitstream/handle/1/20958/Pezerico Vin\%c3\%adcius\%20 Nascimento\%20d e\%200liveira TCC 2020.pdf?sequence=1\&isAllowed=y. Acesso em: 11 ago. 2021.

PIPPO, W. A.; WENCESLAO, R. A. Ch. Cálculo, dimensionamento e desenho de sistema solar fotovoltaico para atender a demanda de recarga de veículos elétricos. 2017. TCC (artigo) Universidade Federal da Integração Latino-Americana, UNILA, Foz do Iguaçu, 2017. Disponível em: https://dspace.unila.edu.br/bitstream/handle/123456789/3198/rodrigo2017.pdf? sequence=1\&isAllowe d=y. Acesso em: 04 ago. 2021.

SILVA, J. E. Veículos Elétricos e a geração distribuída a partir de sistemas fotovoltaicos. 2019. Dissertação (Mestrado) - Universidade Tecnológica Federal do Paraná, Curitiba, 2019. Disponível em: http://repositorio.utfpr.edu.br/sspui/handle/1/4190 Acesso em: 22 ago. 2021.

STAHELIN, K. R. R.; PAULI, M. Estudo de Sistemas de carregamento de carros elétricos para viabilidade em condomínios. 2021. TCC (Graduação) - Universidade do Sul de Santa Catarina, Palhoça, 2021 Disponível em: https://repositorio.animaeducacao.com.br/handle/ANIMA/14547 Acesso em: 24 ago. 2021.

VALLE, H. B. M. Aplicação do conceito Vehicle-To-Grid para nivelamento de carga e suprimento de pico de demanda. 2015. TCC (Graduação) - Universidade Federal do Rio de Janeiro, Rio de Janeiro, 2015.24 Disponível em: http://repositorio.poli.ufri.br/monografias/monopoli10015208.pdf Acesso em: 24 ago. 2021. 